\title{
Detection Range Setting Methodology for Signal Priority
}

\author{
Peter Koonce and John Ringert, Kittelson and Associates \\ Tom Urbanik, University of Tennessee \\ Willie Rotich and Bill Kloos, City of Portland
}

\begin{abstract}
A significant amount of delay to transit vehicles in urban areas is caused by traffic signals. Implementation of signal priority has the potential to reduce control delay caused by traffic signals. The implementation of these systems requires engineering studies that address both transit and traffic signal operations. A comprehensive program requires coordination between the transit agency and the transportation department to address needs of both agencies and users. The City of Portland and the TriCounty Metropolitan Transportation District of Oregon (Tri-Met) have been working on a program that exhibits the elements of such an effort. This article details the efforts of the project and the methodology for developing signal timing and detection distance settings.
\end{abstract}

\section{Introduction}

The City of Portland and Tri-Met have undertaken a program to improve bus service by implementing a signal priority system. The current project is the result of several years of experimentation with various techniques (Kloos and Turner 1999). The system in place uses a 170 HC11 traffic controller, an evolutionary piece of hardware, as part of an eventual upgrade to a 2070-like Advanced Traffic Controller (ATC). The Wapiti software used by the City, the Oregon Department of Transportation (ODOT), and most of the neighboring jurisdictions has been 
upgraded to provide added bus priority features. The implementation allows green extension for the bus phase and red truncation when in nonbus phase(s) while also maintaining coordination. The 3M Opticom system is used as the detection system, and an automatic vehicle location (AVL) system is used to control the emitter.

This research summarizes the issues associated with the implementation of signal priority, specifically the determination of a detection range for an intersection. The detection range for the buses is determined by the location of bus stops upstream of the traffic signal, sight distance to the intersection, extension time available at the intersections, and location of the nearest upstream traffic signal. This article describes the key factors for distance setting and recommends rules for implementation of the range setting. In addition, it examines the bus priority distance setting at one intersection in more detail, providing a summary of the applications and constraints using actual headway and detection range values.

\section{Background}

Portland has a long history of providing signal priority for transit. The light rail system, Metropolitan Area Express (MAX), began service in 1986 with high priority or preemption at many of the signals. The level of priority has steadily increased, allowing more efficient travel between the stations.

Bus priority experience has included three field tests: Powell Boulevard Pilot Project in 1993, Multnomah Boulevard test in 1994, and Tualatin Valley Highway test in 1996. The Powell Boulevard test has been the most publicized (Kloos, Danaher, Hunter-Zaworski 1994). This study evaluated several detection technologies for inclusion in the system. The technologies included the TOTE system by McCain, the LoopComm system by Detector systems, and the Opticom by $3 \mathrm{M}$. Signal priority algorithms were limited in these tests to preserve traffic signal coordination. In each of these tests, Portland's Bureau of Transportation worked with Tri-Met.

Transit signal priority measures include passive, active, real-time, and preemption. 
- Passive strategies attempt to accommodate transit operations through the use of pretimed modifications to the signal system. These adjustments are completed manually to determine the best transit benefit while minimizing the impact to other vehicles. Passive priority can be simple changes to the signal timing or systemwide retiming to address bus operations. The strategies can utilize transit operations information, such as bus link travel times, to determine signal timing coordination plans.

- Active strategies adjust the signal timing after sensing the arrival of a bus. Depending on the application and capabilities of the equipment, active priority may be either conditional or unconditional. Unconditional strategies provide priority regardless of the transit vehicle status (i.e., regardless of passenger loads or lateness).

- Real-time strategies are implemented by systems that provide continuous feedback between the priority request generator (the bus) and the priority request server (unit that discerns which request to serve). Real-time strategies may also use estimated arrival time information at the intersections to make control decisions within the system.

- Preemption could be classified separately because it results in changes to the normal signal phasing and sequencing of the traffic signal. Preemption is most commonly associated with emergency response vehicles and trains. Preemption affects the normal operation of the traffic signal and the resulting traffic flow, which has the potential to impact the safety and efficiency of the intersection. One of the most important effects is the disruption of coordination between traffic signals, which may result in significant congestion.

The Portland application, as in many other cities, is focused on active priority that make changes to the signal timing to accommodate buses while remaining in a coordinated system of traffic signals.

\section{System Description}

Tri-Met is a regional transit agency that serves the three county area in Portland, Oregon. Tri-Met operates 101 bus routes, as well as light rail and paratransit services for seniors and people with disabilities. Tri-Met has continued to 
grow transit ridership by offering exceptional service and continually working to improve the system.

The agency has developed an Intelligent Transportation Systems (ITS) plan to ensure the Portland region is well prepared to realize the benefits of ITS. TriMet has planned projects that support regional integration, build on the agency's existing infrastructure, and offer opportunities for future ITS expansion (Parsons Brinkerhoff, Batelle 2001). One of the 12 projects included in this plan is signal priority. The initial scope of the signal priority project is to provide priority at 250 traffic signals on seven routes in the City. Total project cost is estimated at $\$ 4.5$ million with initial field installation, completed in July 2001, and field-testing to be completed by summer 2002 .

Tri-Met has been using AVL to monitor and control its bus operation for two years. The AVL system uses onboard Global Positioning Systems (GPS) receivers to monitor the buses via the Bus Dispatch System (BDS). The BDS system, developed by Orbital Sciences Corporation, is connected to the vehicle's onboard computer, which contains route and schedule information. Integration of this information allows the bus to determine schedule status on a real-time basis. This permits the Smart Bus concept to only allow the bus to activate the Opticom emitter when the vehicle is behind schedule and if certain other criteria are met.

\section{Project Description}

The first phase of the project involved implementation on Route 104-Division and Route 4-Fessenden in Portland. The Division route operates mainly on SE Division Street. The bus route travels through 31 traffic signals (in each direction), along 10 miles of roadway, extending from downtown Portland to the City of Gresham. The extent of the signal priority project is within the city limits of Portland outside of the city center, stopping 3 miles west of the bus route's eastern terminus, downtown Gresham. This corridor carries 6,500 riders per day with an average load of 26 passengers.

The Fessenden route is more circuitous, traveling on several arterials and collectors in North Portland. The route is approximately 9 miles in length with 33 signals on the outbound route and 25 signals on its inbound route. Portions of the route operate on a couplet outside of the downtown. The Fessenden route carries 7,820 riders per day. 
These routes were good candidates for signal priority because of the spacing of signals, their ridership, and headways ( 7 minutes during the peak hour). The corridors also have a number of simple two-phase intersections, which are simplistic from the traffic engineering perspective. Further, because of the nature of the routes and lower traffic intensities, changes to the signal timing were of less concern on several of the intersections.

An additional advantage of selecting the Opticom system in Portland is that along with signal priority, the traffic signals are also upgraded with emergency vehicle (fire and emergency medical services vehicles only) preemption equipment. The majority of the traffic signals on these routes previously did not have preemption equipment installed because the intersections predated the equipment.

\section{Methodology}

Signal priority consists of two components: the bus must be detected by the traffic signal and the traffic signal must accept the request for priority. As described above, Portland evaluated several detection methodologies in its pilot project and determined that the Opticom system by $3 \mathrm{M}$ would be utilized for bus detection. The Opticom system is currently the most widely used priority and preemption detection system in the United States.

\section{Bus Detection System}

The challenge for implementing the concept successfully is the detection system, which must place a call at an appropriate time in order to be effective. A call placed too late during the bus phase can result in a missed opportunity. A call placed to soon can result in the provision of green time that cannot be used effectively.

The Opticom system is relatively simple: data are transmitted from the bus to the traffic signal via an emitter and an optical detector. An emitter mounted on the bus is activated to send an encoded message to the traffic signal. A detector located at the intersection receives the signal and converts it to a message to the controller. A phase selector within the controller cabinet makes the request for priority within the traffic signal controller and also logs the information within the unit. 
Opticom can provide two pieces of information. First, the system requests an immediate request for service. This request for service can be controlled in two ways. The bus, using the Smart Bus concept, controls the time of the request. The detection range setting of the Opticom receiver controls the time of the request. The Opticom transmitter can also provide a bus identification number, which can be used to distinguish bus types. Setting the distance for the detection range provides an opportunity to increase the usefulness of the priority request by requesting priority at a location that increases the likelihood that the bus will progress through the signal during the priority call. Other criteria that control the emitter within the Smart Bus concept are shown in Figure 1. The Smart Bus only activates the emitter when the bus is on route, in service for passengers, its doors are closed, or when the bus is running late. The threshold for determining whether the bus is late is set at 90 seconds. Once the bus has reached this threshold and is behind schedule, the emitter will be active until it has gained $60 \mathrm{sec}-$ onds and is less than 30 seconds behind schedule.

\section{Traffic Signal Timing}

The traffic signal software used by the City provides a range of priority and preemption options as well as recovery options to reduce bus delays. The strategies are in place throughout the day while buses operate on the system. Priority can be requested on any of the legs of the intersection. The maximum extension is constrained by intersection elements, but range from 0 to 40 seconds. The truncation also is dependent on the configuration of the intersection. Table 1 summarizes some of the limitations associated with the signal timing as it relates to bus operations.

During this implementation, red truncation and green extension are utilized to provide priority. The basic concept of green extension and red truncation is generally well understood. The maintenance of coordination requires that the phase length changes be implemented within the constraints of the overall cycle length; considerations include minimum walk time, flashing DON'T WALK time, and minimum vehicle green time. 


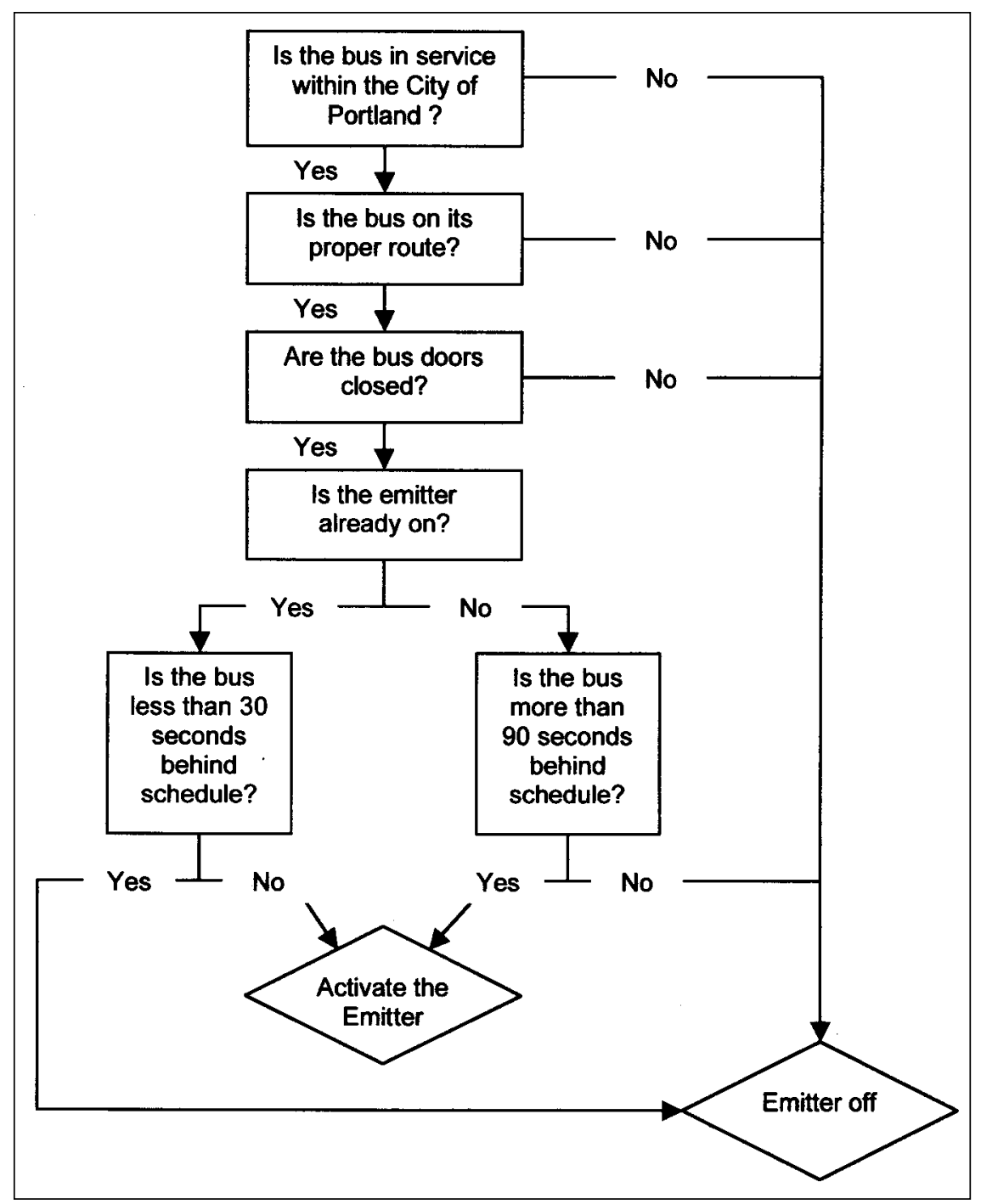

Figure 1. Decision framework for emitter activation 


\begin{tabular}{|lll|}
\hline & Traffic Signal Timing Considerations for Signal Priority \\
\hline Parameter & Limitation & Comment \\
\hline $\begin{array}{l}\text { Pedestrian } \\
\text { detection }\end{array}$ & $\begin{array}{l}\text { Lack of pedestrian detection (push } \\
\text { buttons for actuation) requires the opposing } \\
\text { pedestrian phase to time every cycle }\end{array}$ & $\begin{array}{l}\text { Presence of pedestrian detection } \\
\text { increases the potential responsiveness } \\
\text { of the intersection to serve transit }\end{array}$ \\
$\begin{array}{l}\text { Pedestrian } \\
\text { timing }\end{array}$ & $\begin{array}{l}\text { Time for flashing Don't Walk cannot } \\
\text { be reduced in any case }\end{array}$ & $\begin{array}{l}\text { Pedestrian detection reduces the need } \\
\text { to recall pedestrian phases each cycle, } \\
\text { thereby improving the responsiveness } \\
\text { to transit }\end{array}$ \\
$\begin{array}{l}\text { Multiphase } \\
\text { intersections }\end{array}$ & $\begin{array}{l}\text { Phase skipping is not allowed in the } \\
\text { State of Oregon; thus minimum vehicle } \\
\text { times and clearance times must be } \\
\text { considered for all phases (legislative } \\
\text { limitation) }\end{array}$ & $\begin{array}{l}\text { Additional phases at intersections } \\
\text { increase the amount of required time } \\
\text { for service }\end{array}$ \\
$\begin{array}{l}\text { Cycle } \\
\text { lengths }\end{array}$ & $\begin{array}{l}\text { Low cycle lengths reduce the flexibility } \\
\text { of the engineer to extend the timing } \\
\text { provide better responsiveness overall }\end{array}$ & $\begin{array}{l}\text { The trade-off between flexibility and } \\
\text { efficiency at the intersections has been } \\
\text { consistently discussed; lower cycle } \\
\text { length typically improves bus operations }\end{array}$ \\
\hline
\end{tabular}

\section{Priority Decision Logic}

The time the call is entered dictates the response of the controller. The controller logic determines whether to use green extension (extend a current green indication for the bus) or red truncation (shorten other nonbus phases), depending on whether the controller is in the bus or nonbus phase, respectively. In the case of a simple two-phase intersection, the logic is simplified, and for purposes of discussion, this case will be reviewed. To set the detection range, both extension and truncation must be considered to determine an appropriate distance from the intersection. A procedure developed as a part of this project establishes the location of Opticom detectors on the bus line and determines the range at which the detector will identify the bus and initiate the bus priority plan. As shown in Figure 2, the decision is based on the current status of the bus phase when the call is received.

\section{Priority Distance Setting}

Establishing the priority distance is a critical portion of the implementation. Ideally, the detection would occur at the furthest upstream point to give advanced 
notice for the approach of the buses. Because the Opticom system results in an immediate request for service, the distance from the traffic signal at which the call is received dictates the length of the extension possible. To address limitations, the detection range is set to reduce the length of the call based on the amount of priority time that is available within the extension portion of the priority service. Essentially, the length of advance time that can be accommodated is limited by lack of knowledge on the desired time of service and limitations in the controller software's decision-making logic. The maximum advance time is the length by which the bus phase can be extended.

For purposes of further explanation, a simple two-phase intersection with buses on both phases will be described. While simplistic, the explanation is also practical because the intersection of N. Albina Avenue and N. Killingsworth Street is exactly this configuration. As shown in Figure 3, Route 4 Fessenden operates on phase 2 (N. Albina Avenue) and Route 72 Killingsworth operates on the cross-street phase 4. At this intersection, the coordinated movement is Killingsworth Street (the north-south movement).

\section{Green Extension Distance-Setting Procedure}

The green extension plan is used when the call is received on a phase that is already green (i.e., a call on phase 2 is received from Route 4 while phase is

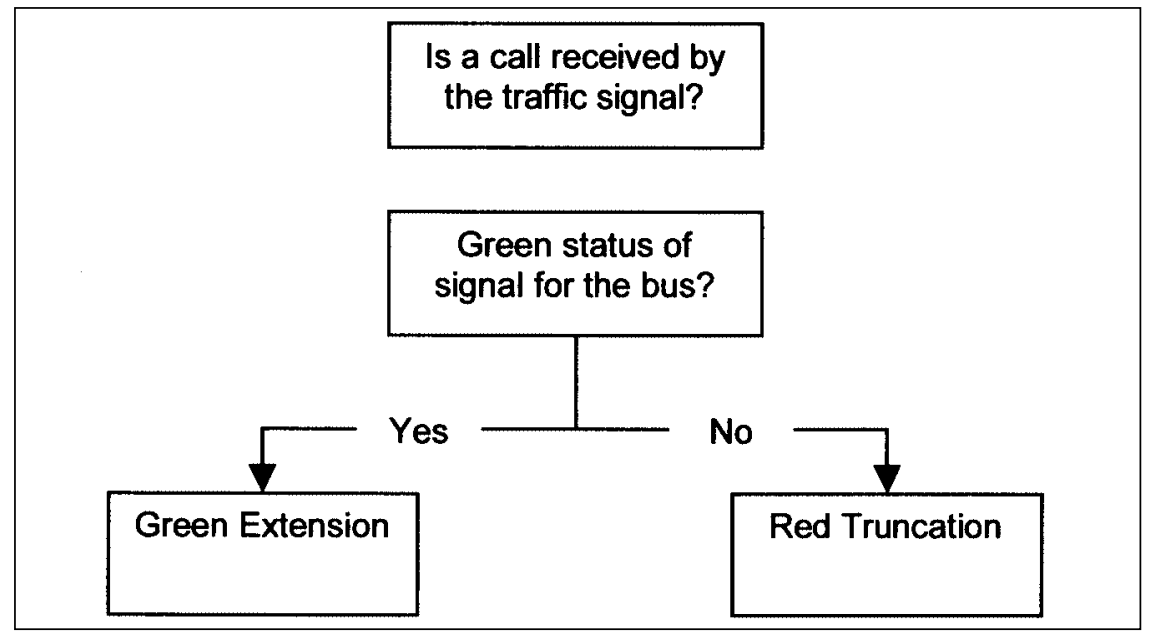

Figure 2. Decision framework for priority plan selection 


\begin{tabular}{|c|c|}
\hline \multicolumn{2}{|c|}{$\begin{array}{c}\text { Table } 2 \\
\text { Traffic Signal Timing Descriptions }\end{array}$} \\
\hline \multirow[t]{2}{*}{ Treatment } & Description \\
\hline & Passive Priority \\
\hline Adjust cycle length & $\begin{array}{l}\text { Reduce cycle lengths at isolated intersections } \\
\text { for the benefit of the bus. }\end{array}$ \\
\hline Split phases & $\begin{array}{l}\text { Introduce special phases at the intersection } \\
\text { for the bus movement while maintaining } \\
\text { original cycle length. }\end{array}$ \\
\hline Areawide timing plans & $\begin{array}{l}\text { Preferential progression for buses through } \\
\text { signal offsets. }\end{array}$ \\
\hline Bypass metered signals & $\begin{array}{l}\text { Buses use special reserved lanes, special } \\
\text { signal phases, or are rerouted to nonmetered } \\
\text { signals. }\end{array}$ \\
\hline \multirow[t]{2}{*}{ Adjust phase length } & Increased time for approaches with buses. \\
\hline & Active Priority \\
\hline Green extension & Increase phase time for current bus phase. \\
\hline Early start (red truncation) & Reduce other phase times. \\
\hline Special phase & Addition of a bus phase. \\
\hline \multirow[t]{2}{*}{ Phase suppression } & Skipped nonpriority phases. \\
\hline & Real-Time Priority \\
\hline Intersection Control—Delay & $\begin{array}{l}\text { Signal timing changes to reduce overall } \\
\text { person delay. }\end{array}$ \\
\hline \multirow{3}{*}{$\begin{array}{l}\text { Optimizing } \\
\text { Network Control }\end{array}$} & Signal timing changes considering the overall \\
\hline & system performance. \\
\hline & Preemption \\
\hline Preemption (Unconditional) & $\begin{array}{l}\text { Bus phase begins when all other intervals are } \\
\text { satisfied. }\end{array}$ \\
\hline Preemption (Conditional) & $\begin{array}{l}\text { Same as above except certain conditions are } \\
\text { used to determine when the bus phase should begin. }\end{array}$ \\
\hline
\end{tabular}

green). See Figure 2. The controller coordination timing and the demand of the side street limit the amount of green extension that can be provided. Assuming a call is received before the onset of yellow for the bus phase, the extension of the bus priority algorithm will start timing at the yield point. If a call was received at the yield point in this case, the extension time would be equal to the travel time between the detection point and the intersection. This represents the worst case under extension. 


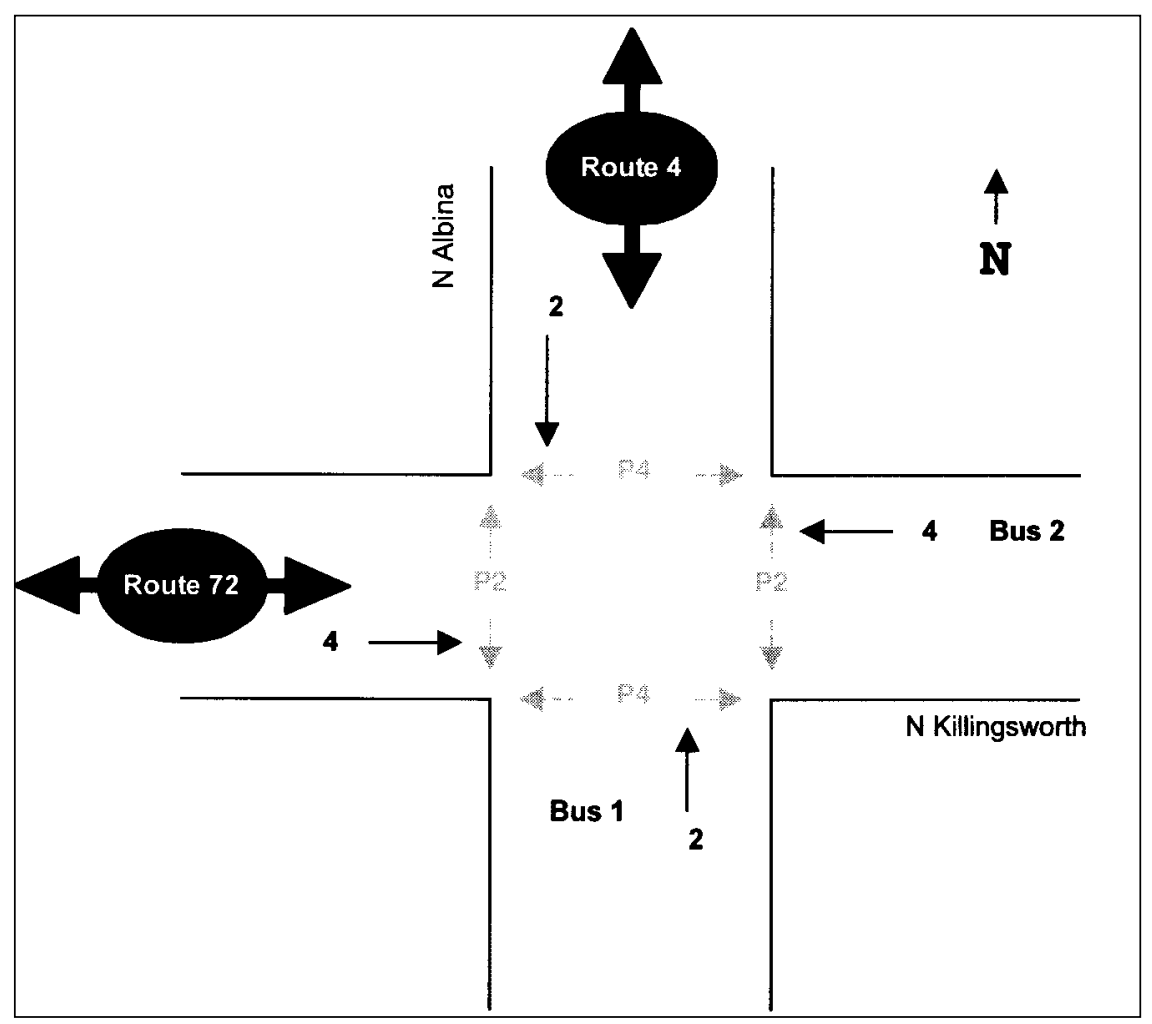

Figure 3. Case study intersection: N Albina/ N Killingsworth

Coordinated Bus Phase Green Extension. In this case (Route 4 bus on phase 2), a call arrives during the green interval for phase 2 . The limitation for green extension is determined by the minimum times for the phase 4 WALK, FLASH Don'T WALK (FDW), Yellow and All Red clearance intervals (Y+AR), and the minimum WALK (typically 4 seconds) for phase 2 . This assumes that the bus phase (phase 2) of the next cycle maintains the phase 2 yield point (start of FDW) for the next cycle after the bus call has arrived. This practice preserves the coordination with the adjacent signals.

Noncoordinated Bus Phase Green Extension. For the noncoordinated phase (bus on phase 4), the lengthen plan is similar to what was described above. In this case, the phase 2 forceoff (start of FDW) remains zero and the phase 4 $\mathrm{Y}+\mathrm{AR}$ must be accommodated, followed by the minimum phase 2 WALK time. 
In either of these cases, it is desirable to set the range to a distance equal to the travel time associated with the extension time available. This approach limits the amount of unutilized priority provided and ensures that once a call is received and an extension plan is initiated the bus will pass through the intersection during the current cycle.

\section{Red Truncation Plans Distance Setting}

Red truncation is activated when a call is received on a phase that is not green. Red truncation reduces the length of the other (nonbus) phases to return to the bus phase earlier. In this scenario, the forceoffs for all phases change from their normal value. The worst case under the shorten plan is a received call that does not allow a truncation. Truncation is limited by the amount of time required for the recalled phases (pedestrian and vehicle).

Coordinated Nonbus Phase Red Truncation. The nonbus phase is truncated to the new forceoff associated with the bus plan. Truncating the nonbus phase allows an earlier return to the bus phase. In a two-phase intersection, the shorten plan is limited by the minimum times for the WALK, FDW, and Y+AR. The truncation benefit is provided in what normally would be a solid Don't WALK (DW) indication for phase 4. In some instances, WALK timing for phase 4 was reduced to provide more flexibility for the buses.

Noncoordinated Bus Phase Red Truncation. The City's signal timing policy maximizes the WALK portion of the coordinated phase. For this reason, the red truncation plan requires a forceoff that truncates the WALK portion and initiates the FDW before its normal forceoff. In this case, the truncation value should be set to reduce the WALK to an amount that allows the early return to the noncoordinated phase (phase 4).

In either case, it is desirable to set the range to a distance greater than the coordinated phase FDW value, so that the bus can be detected with adequate time for the controller to react. Provided that the proper sight distance exists and the bus stop spacing allows, the green extension and red truncation plans can be developed so that a bus will not stop at a traffic signal under off-peak traffic conditions. 


\section{Operational Issues of Bus Arrival}

The arrival of the bus at the traffic signal is dependent on the speed at which the vehicle is traveling, the impedance it experiences, and the stops that it makes. These three factors may reduce the range at which it is desirable to place a low priority call to the controller. As discussed, providing priority to the bus phase prematurely may not only delay the bus, but it also may reduce the effectiveness of the traffic signal in its capacity to serve nonbus phase traffic. Each of these factors was examined to identify operational results associated with the arrival of the bus at the intersection.

\section{Bus Travel Speed}

To set the detection range, the assumed travel speed for the bus was set to equal the speed limit. In some cases, where the speed limit was greater than the expected speed, a lower value was used. A lower value was also considered in areas of denser development, where on-street parking, increased pedestrian activity, and numerous access driveways can slow the average speed of buses.

\section{Bus Impedance}

The impedance the bus experiences en route to the bus stop could result from pedestrians, cyclists, or parked vehicles. Bus impedance was incorporated into the travel speed where possible. Field studies during implementation may provide more insight as to the modifications necessary to accommodate special situations.

\section{Stop Location}

Nearside bus stops have been the subject of considerable debate. Nearside stops have the potential to render a call useless due to bus boarding and alighting in advance of the traffic signal. The initial operating concept was to set the range of the emitter at a distance 40 feet past the upstream bus stop (between the bus stop and the next traffic signal). This would eliminate the potential of a bus requesting priority and then stopping upstream, thereby eliminating the need for the priority.

Field tests of the Opticom emitter determined that in several locations this approach limits the range to less than 300 feet, reducing the overall effectiveness of the system. The potential limitation suggests more careful review of the bus stop location, possibly relocating it to the far side of the intersection. 
When a bus places a priority call and has to stop upstream of the intersection, the call may be inappropriate. This occurs frequently because bus stop spacing standards place stops every two blocks (300 to 700 feet upstream of the traffic signal) in many areas throughout the City. To increase the effectiveness of the priority system, the rules were created for the range setting:

(The range will be set to maximize detection time in advance of the traffic signal, provided the following rules are followed. The smallest value from these three rules will be used to set the range for the detector.)

- Rule 1-Extension Time Distance: The allowable range calculation will be based on the extension time available in the controller. The speed limit will be used to convert the extension time to an appropriate distance. Truncation time should not be the criterion, since the benefit of the truncation suggests additional green time following the truncation should allow bus passage.

- Rule 2-Bus Stop Distance: The range should be 40 feet downstream of the bus stop closest to the traffic signal (disregarding nearside stops).

- Rule 2A-Modification to Bus Stop Distance: The first upstream bus stop will be disregarded if it is within 400 feet of the traffic signal and calculations per Rule 1 provide a distance greater than 900 feet. In this case, the distance of the second upstream bus stop will be used for comparison with the extension time distance.

- Rule 2B-Stop Utilization Modification: Tri-Met's AVL data will be reviewed to determine the percentage of buses that stop at the upstream bus stop. If this number is greater than half, Rule 2 will be followed.

- Rule 3-Traffic Signal Distance: The distance to the nearest upstream traffic signal will be noted to eliminate the potential of a priority call being received simultaneously at two signals, as this may lead to ineffective calls.

Rule 2A was created to reduce the limitation of closely-spaced bus stops on the priority corridors. At many of the intersections on the Fessenden and Division routes, the Extension Time Distance exceeds the Bus Stop Distance. To reduce the effect of Rule 2 at locations where the first upstream stop is seldom used, Rule 
2A was created. In cases where Rule 2 is overly restrictive, the second upstream stop will be used as the criteria to compare the extension distance. The logic behind this decision was that the controller could recover from a call that is lost at an upstream stop, but it is less desirable to have two interruptions in the normal system resulting in poor responsiveness when the bus arrives at the traffic signal.

Ideally, information regarding stop frequency would be used to determine whether the bus stop upstream of the traffic signal should be considered. In this initial implementation, no data have been provided and thus only anecdotal observations will be used to determine whether the bus stops may be disregarded.

\section{Results}

The bus priority system has been implemented at 58 of the 72 intersections on Routes 4 and 104. For evaluation of the bus operation, Tri-Met's AVL system has been used to record the results for the implementation. Each route has been cut into segments to delineate the effects at each traffic signal. The segments vary from 800 to 2,500 feet and include up to three signals. Tri-Met's AVL system records many different pieces of data about every time any bus passes by a bus stop. The system records arrival time near a segment to initialize the start of the segment time and segment end time to identify the total travel time for each segment.

Early results have shown that improvements in travel time typically range from 5 to 8 percent of the overall travel time. On certain segments, the travel time reduction increases to as much as 24 percent of the travel time, but the value is highly dependent on several factors such as the length and the number of traffic signals within the segment.

\section{Bus Priority Distance Setting Example: Northeast 33rd/Sandy}

To illustrate the various points made above, we have chosen the Northeast 33rd/Sandy intersection to provide some additional context related to the priority distance setting. This example presents a summary of the application and constraints of the experience using actual headway and detection range values. 


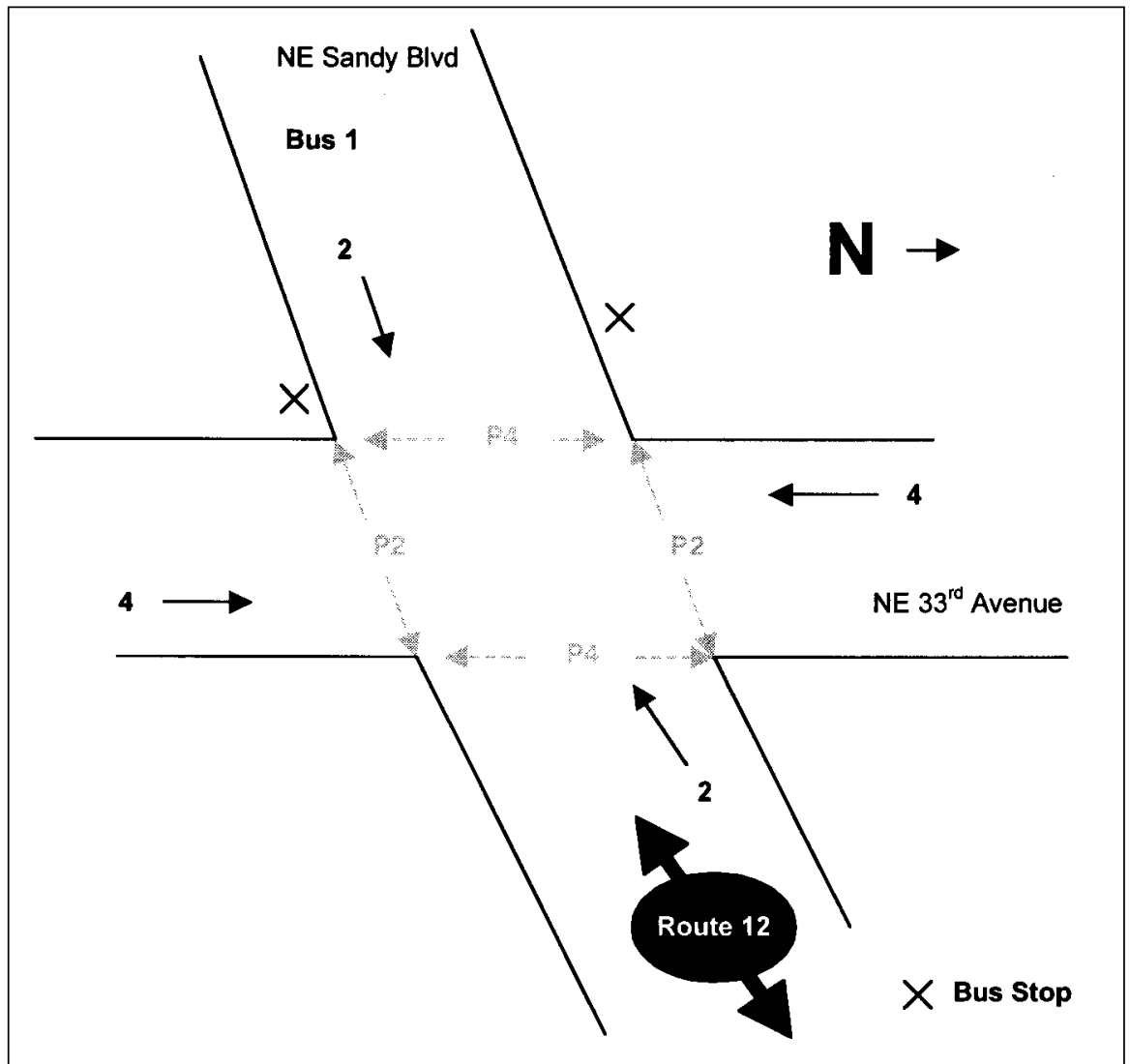

Figure 4. NE 33rd/Sandy intersection

Intersection Characteristics

This particular intersection was chosen as an example because it features both a nearside (inbound direction) and a farside (outbound direction) bus stop as shown in Figure 4. The Sandy Route 12 travels on the Northeast Sandy Boulevard corridor operating at 10-minute headways during peak periods. The speed limit in this vicinity is $30 \mathrm{mph}$.

\section{Bus Travel Speed}

On Sandy Boulevard, the assumed travel speed for the bus was set lower than the speed limit because of the nature of the corridor in this area. As shown in Figures 5 and 6, bus ridership and short stop spacing along this corridor result in low average speeds. Based on field observations, $15 \mathrm{mph}$ was used. 


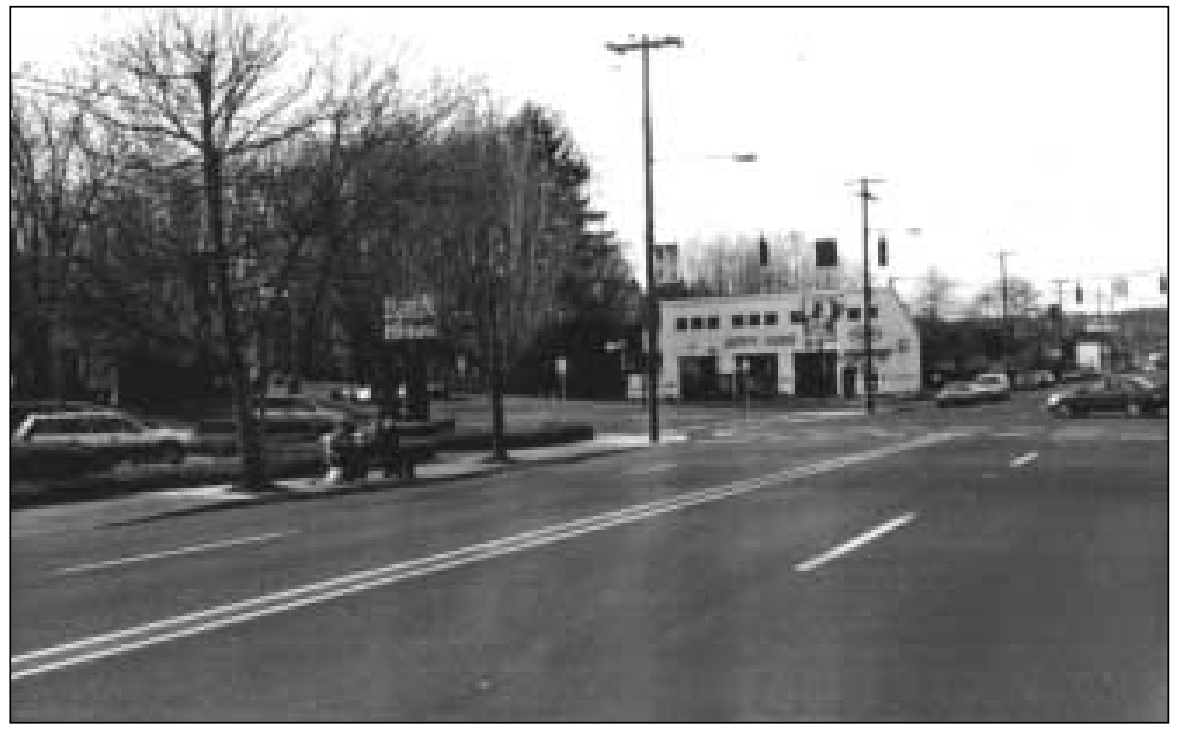

Figure 5. Farside stop at NE 33rd/Sandy (outbound direction)

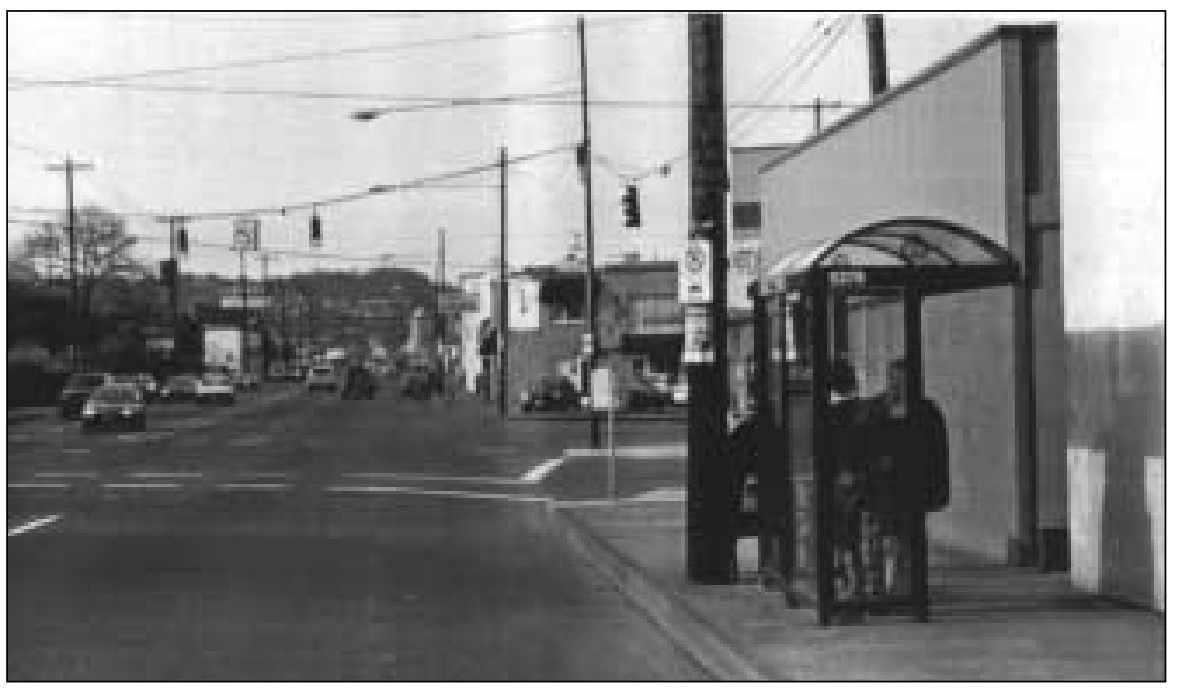

Figure 6. Nearside stop at NE 33rd/Sandy

(inbound direction) 
- Rule 1-Extension Time Distance: The allowable range calculation is based on the extension time available in the controller. This intersection is a simple two-phase intersection operating on a 100-second cycle during peak periods and, therefore, is not limited by the extension plan because approximately 30 seconds can be lengthened for the bus phase. Using $15 \mathrm{mph}$ (22 feet per second) as the travel speed yields 660 feet for Sandy Boulevard. For the approach with the nearside stop, ridership would be evaluated to determine limitations to the extension time.

- Rule 2-Bus Stop Distance: The range should be 40 feet downstream of the bus stop closest to the traffic signal (disregarding nearside stops). For the outbound direction (farside stop), the distance was set based on this rule because Rule 1 was not a limiting factor.

- Rule 2A-Modification to Bus Stop Distance (40 feet downstream of second stop): In the case of the inbound route, the nearside stop significantly limits the priority distance that can be set. Using the second stop would yield a distance of 445 feet.

- Rule 2B-Stop Utilization Modification: Review of bus ridership data showed that the bus stops on 58 percent of the runs pass this intersection during the P.M. peak hour. For this reason, it was assumed the bus would stop at the nearside location and the distance was set to 40 feet downstream of the stop.

- Rule 3-Traffic Signal Distance: The distance to the nearest upstream traffic signal is not a factor at this intersection.

Table 3 summarizes the case study example in a tabular format.

\section{Conclusions}

Signal priority offers the promise to improve schedule reliability and reduce travel time through traffic signals. However, the complexities of bus operations suggest that more sophisticated decision logic will be necessary to achieve all the benefits of signal priority. The use of the AVL system in conjunction with the signal priority reduces the number of requests to the traffic signal, thereby reducing the effectiveness of the system, and requires an iterative approach to scheduling. 


\begin{tabular}{|c|c|c|}
\hline \multicolumn{3}{|c|}{$\begin{array}{c}\text { Table } 3 \\
\text { NE Sandy/33rd Avenue Intersection Tri-Met Route } 12\end{array}$} \\
\hline & \multicolumn{2}{|c|}{ Rule 1} \\
\hline & & Distance \\
\hline & $\begin{array}{l}\text { Extension } \\
\text { Time }(f t)\end{array}$ & $\begin{array}{l}\text { Between } \\
\text { Stops }(f t)\end{array}$ \\
\hline Inbound (nearside) & 660 & 485 \\
\hline \multirow[t]{3}{*}{ Outbound } & 660 & 676 \\
\hline & \multicolumn{2}{|c|}{ Rule 2} \\
\hline & $\begin{array}{l}\text { Distance from } \\
\text { Signal of Unstream } \\
\quad \text { Stp (ft) }\end{array}$ & $\begin{array}{c}\text { Stop } \\
\text { Utilization }\end{array}$ \\
\hline Inbound (nearside) & 109 & $58 \%$ \\
\hline \multirow[t]{4}{*}{ Outbound } & 549 & $69 \%$ \\
\hline & \multicolumn{2}{|c|}{ Rule 3} \\
\hline & Distance Between & Critical \\
\hline & $\begin{array}{l}\text { Signal and Upstream } \\
\text { Signal (ft) }\end{array}$ & $\begin{array}{c}\text { Critical } \\
\text { Distance }(f t)\end{array}$ \\
\hline Inbound (nearside) & 1,718 & 69 \\
\hline Outbound & 1,928 & 549 \\
\hline
\end{tabular}

AVL also promises to make the use of the emitter more selective depending on the status of the bus and boarding and alighting passengers. Further, measures supportive of signal priority such as the relocation of bus stops to the far side of each signalized intersection and the provision of stops at a distance upstream that increases the allowable range for the detection system. 


\section{Acknowledgements}

The authors extend thanks to fellow staff from the City of Portland, Kittelson \& Associates, Inc., and Tri-Met who in working on the project have made this implementation an enjoyable undertaking.

\section{References}

Kloos, W. C., and K. Turner. 1999. Implementing traffic signal priority for buses. Compendium of Technical Papers. Institute of Transportation Engineers.

Kloos, W. C., A. R. Danaher, and K. M. Hunter-Zaworski. 1994. Bus priority at traffic signals in Portland: The Powell Boulevard pilot project. Compendium of Technical Papers. Institute of Transportation Engineers: 420-424.

Parsons Brinkerhoff, Batelle. 2001. Tri-Met 5-year Intelligent Transportation Systems plan. Final Report. Portland, Oregon.

\section{About the Authors}

Peter Koonce (pkoonce@kittelson.com) is an engineer with Kittelson \& Associates and is based out of the Portland, Oregon, office. Mr. Koonce holds an undergraduate degree from Oregon State University and a Master of Science from Texas A\&M University. He is a registered Professional Engineer in the State of Oregon.

ToM URBANIK (turbanik@utk.edu) is a professor and Chair of Excellence in Transportation at the University of Tennessee in Knoxville. Dr. Urbanik received a Ph.D. from Texas A\&M University, Master of Science in civil engineering from Purdue University, Bachelor of Science in civil engineering from Syracuse University, and a Bachelor of Science in forest engineering from the New York State College of Environmental Science and Forestry. He is a registered engineer in Michigan and Texas.

BILL KLOOS (Bill.Kloos@trans.ci.portland.or.us) is the signal system manager for the City of Portland, Oregon. In that capacity, he manages the Traffic Signals/Street Lighting/ITS Division responsible for the planning, design, construction, operation, and maintenance of nearly all the traffic signals and streetlights within Portland. Mr. Kloos is a graduate of Montana State University. 
WILLIE RoTICH (Willie.Rotich@trans.ci.portland.or.us) is the ITS engineer for the City of Portland. Mr. Rotich was the project manager for the City of Portland on the Transit Signal Priority project. He is a graduate of Oregon State University.

JoHN RINGERT (jringert@kittelson.com) is the consultant team project manager for Kittelson \& Associates. He has more than 11 years experience in traffic design, traffic engineering, and planning. Mr. Ringert received a Bachelor of Science degree from the University of Idaho and received a Master of Science degree from Texas A\&M University. 